Abstracta Iranica Abstracta Iranica

Revue bibliographique pour le domaine irano-aryen

Volume 25 | 2004

Comptes rendus des publications de 2002

\title{
Man and Cosmos in Ancient Iran. Serie Orientale Roma XCI, Roma, Istituto Italiano per l'Africa e l'Oriente, 2001, 147 p., 1 pl.
}

\section{Rika Gyselen}

\section{(2) OpenEdition}

Journals

Édition électronique

URL : http://journals.openedition.org/abstractairanica/4782

DOI : $10.4000 /$ abstractairanica.4782

ISSN : 1961-960X

Éditeur :

CNRS (UMR 7528 Mondes iraniens et indiens), Éditions de l'IFRI

Édition imprimée

Date de publication : 15 mai 2004

ISSN : 0240-8910

Référence électronique

Rika Gyselen, « Man and Cosmos in Ancient Iran. Serie Orientale Roma XCl, Roma, Istituto Italiano per I'Africa e l'Oriente, 2001, 147 p., 1 pl. », Abstracta Iranica [En ligne], Volume 25 | 2004, document 216, mis en ligne le 15 mars 2006, consulté le 25 septembre 2020. URL : http://journals.openedition.org/ abstractairanica/4782 ; DOI : https://doi.org/10.4000/abstractairanica.4782

Ce document a été généré automatiquement le 25 septembre 2020.

Tous droits réservés 


\title{
Man and Cosmos in Ancient Iran. Serie Orientale Roma XCI, Roma, Istituto Italiano per l'Africa e l'Oriente, 2001, 147 p., 1 pl.
}

\author{
Rika Gyselen
}

1 Ce livre comporte le texte des conférences données dans le cadre des "Ratanbai Katrak Lectures" (Oxford, 1996) dont le thème a trait au concept que l'homme a de lui-même dans sa réalité physique et spirituelle. L'A. cerne le suj et à partir de cinq approches.

2 La première a trait aux trois âmes immortelles, c'est-à-dire la dēn, le frawahr et le ruwān et à quelques autres aspects de l'homme comme les facultés de la connaissance ou celles de la perception. Le deuxième chapitre aborde la composition du corps à travers des textes qui traitent de l'anatomie, la physiologie, et la médecine. Une attention particulière est portée à la médecine grecque, parvenue aux mazdéens par l'intermédiaire de la médecine syriaque. Le troisième chapitre a trait à la relation de l'homme au cosmos et à la théorie de la relation micro-macrocosme. Le quatrième chapitre aborde le chamanisme qui est un des moyens que l'homme utilise pour établir une relation avec le monde invisible. Dans le cinquième chapitre l'A. examine les liens qui existent parfois entre le chamanisme et la magie et dans le sixième quelques aspects de l'identité mazdéenne: l'orthodoxie, le réformisme, la conver-sion et le prosélytisme.

3 Cet ouvrage foisonne d'idées et d'interprétations originales souvent dues à l'utilisation de sources auparavant peu utilisées dans ce type d'approche : on peut citer le traité de Zādspram (publié par Ph. Gignoux et A. Tafazzoli en 1993) et l'utilisation intensive de sources syriaques. 
INDEX

Thèmes : 6.1. Zoroastrisme

\section{AUTEURS}

RIKA GYSELEN

CNRS - Paris 